Eur. J. Clin. Chem. Clin. Biochem.

Vol. 31, 1993, pp. 815-827

(C) 1993 Walter de Gruyter \& Co.

Berlin - New York

Prolactin Heterogeneity:

\title{
A Limitation on the Evaluation of Results from Prolactin Assays due to Differences in Immunoassays and the Different Bioactivities of Prolactin Forms
}

\author{
By B. Löhrke ${ }^{1}$, S. Kunkel ${ }^{2}$, Jutta Köwitz ${ }^{3}$, T. Viergutz ${ }^{1}$, Ute Tiemann ${ }^{1}$, Hannelore Alm ${ }^{1}$ and B. Krüger ${ }^{4}$ \\ ${ }^{1}$ Forschungsinstitut für die Biologie landwirtschaftlicher Nutztiere Dummerstorf-Rostock \\ ${ }^{2}$ Frauenklinik der Fakultät für Medizin der Universität Rostock \\ ${ }^{3}$ Forschungslabor der Orthopädischen Klinik der Fakultät für Medizin der Universität Rostock \\ ${ }^{4}$ Institut für Medizinische Biologie der Fakultät für Medizin der Universität Rostock, Germany
}

(Received November 25, 1992/August 13, 1993)

Summary: Prolactin exists in biological fluids in several molecular forms. This raises two questions:

(1) whether the assay of prolactin by immunotechniques is valid and reliable and

(2) whether the different forms have different physiological roles, which might be exploited to improve diagnostic accuracy and data interpretation by the use of appropriate methods.

To investigate these questions, prolactin from human amniotic fluid was separated, by concanavalin ASepharose affinity chromatography, into bound, retarded and unbound fractions (bound prolactin fraction, retarded prolactin fraction, unbound prolactin fraction), which were characterized by electrophoresis, immunoblotting and glycan detection blot. Virtually no contamination was found in the bound prolactin fraction, and the unbound prolactin fraction and retarded prolactin fraction were $74-83 \%$ pure according to densitometry of the electrophoretic and immunoblot patterns. High variability was found among the individual patterns. Glycan detection in the blotted fractions revealed that the bound prolactin fraction bands corresponding to $M_{\mathrm{r}} 25000-29000$ were weakly glycolysated, whereas the bands of $M_{\mathrm{r}} 60000-64000$ were significantly glycan-positive. Immunoreactive bands of unbound prolactin fraction and retarded prolactin fraction also stained positively for glycans. Using two commercial prolactin kits, the bound prolactin fraction forms were virtually undetectable. To demonstrate that the prolactin forms may depend on the hypothalamic state, two behaviourly different breeds of cattle were used as an animal model for studying hypothalamic activities. The number of immunoreactive bands, representing the prolactin forms, and the change of the forms in response to thyroliberin differed strikingly among the groups.

The bioactivity of the forms was examined in bovine granulosa, oviductal, endometrial and spleen cells, and in murine splenocytes, the latter being activated by concanavalin $\mathrm{A}$ or allogeneically to create in vitro conditions that may have relevance for situations in vivo. The rate of incorporation of $\left[{ }^{3} \mathrm{H}\right]$ thymidine in murine splenocytes was dose-dependently enhanced only by bound prolactin fraction. The increase was abolished by purified anti-prolactin antiserum. However, the standard prolactin from the kits inhibited the proliferation even in low dose $(1.25 \mu \mathrm{g} / \mathrm{l})$ and the inhibition was abolished in part by bound prolactin fraction. Thymidine incorporation into the bovine cells was significantly increased by low concentrations $(2 \mu \mathrm{g} / \mathrm{l})$ of unbound prolactin fraction and retarded prolactin fraction. Oviduct epithelial cells and splenocytes were stimulated by unbound prolactin fraction but not by retarded prolactin fraction in a dose of $16 \mu \mathrm{g} / \mathrm{l}$. Thymidine incorporation into granulosa cells was inhibited by retarded prolactin fraction $(16 \mu \mathrm{g} / \mathrm{l})$ but not by unbound prolactin fraction. 
Thus, various prolactin forms can have not only different but also opposite effects in a cell system that models a given physiological situation in vivo, suggesting that both immuno- and bioassays need to be carefully defined, if measurements of prolactins are to be valid and reliable.

\section{Introduction}

The prolactin concentration in serum is a commonly used diagnostic quantity for human reproductive disorders. However, the existence of prolactin in several molecular forms raises questions regarding both the accuracy of prolactin assays and the diagnostic significance of the determined values. When prolactin is assayed with immunotechniques, the accuracy depends on the antigenic similarity between the forms. Prerequisite for reliable diagnosis is a knowledge of the physiological significance of the molecular form detected. Recently, growing evidence has demonstrated that prolactin patterns are altered according to the physiological situation (1) and that the prolactin forms differ in their bioactivities $(2-5)$. Without further elucidation of the dissimilarities in the properties and functions of prolactin forms, the mechanism by which prolactin interferes with particular stages of the reproductive process may remain controversial. A better understanding of the biological significance of the molecular forms is needed to clarify their diagnostic value. We therefore investigated the molecular heterogeneity, the degree of glycosylation and the immuno- and bioactivities of prolactin fractions, separated by concanavalin A-Sepharose from human amniotic fluid, and studied the relation between circulating prolactin forms and hypothalamic activity.

\section{Materials and Methods}

\section{Animals}

Mice were obtained from an outbreeding colony maintained in the Department of Population Biology under clean conditions and were provided with water and commercial laboratory food (Altromin) ad libitum. The reproductive organs were from heifers (Friesian cattle) slaughtered in the local slaughter house. In experiments in which the alteration of the circulating prolactin pattern was challenged by hypothalamic peptides, four young bulls aged 12 months of two breeds of cattle (Galloway and Friesian) and two control animals were used in each case. The animals were kept in the experimental station of our institute and provided with food with a calorific value sufficient for maintenance.

\section{Murine splenocytes}

The spleens were minced and passed through a nylon mesh (pore size $40-45 \mu \mathrm{m}$ ) by gentle grinding and flushing with complete RPMI containing $0.001 \mathrm{~mol} / 1$ ethylenediaminetetraacetic acid (EDTA). The ingredients of the complete RPMI medium were: RPMI 1640 with $L$-glutamine, Hepes $(0.02 \mathrm{~mol} / \mathrm{l})$ $\mathrm{pH} 7.2$, streptomycin $(160 \mathrm{mg} / \mathrm{l})$, fungizone (Squibb, $4 \mathrm{mg} / \mathrm{l}$ ), nutridoma (Boehringer, $10 \mathrm{~g} / \mathrm{l}), \beta$-mercaptoethanol $(50 \mu \mathrm{mol} / \mathrm{l})$. Materials were from Serva when not otherwise stated.

Erythrocytes were lysed by addition of 10 volumes lysis solution $\left(7 \mathrm{~g} / 1 \mathrm{NH}_{4} \mathrm{Cl}, 1.5 \mathrm{~g} / \mathrm{l} \mathrm{NaCl}, 0.02 \mathrm{~mol} / \mathrm{l}\right.$ Hepes, $0.0012 \mathrm{~mol} / \mathrm{l}$ $\mathrm{Na}_{2} \mathrm{CO}_{3}, 0.001 \mathrm{~mol} / \mathrm{l}$ neutralized EDTA), and gentle shaking for $2 \mathrm{~min}$. Following centrifugation $(900 \mathrm{~g}, 4 \mathrm{~min})$ the cells were resuspended in distilled water at room temperature to remove residues of the lysis solution and water soluble precipitates.

After $15 \mathrm{~s}$, dissolved $\mathrm{NaCl}$ was added to a final concentration of $8.5 \mathrm{~g} / \mathrm{l}$. The cells were centrifuged $(600 \mathrm{~g}, 5 \mathrm{~min})$ and resuspended in complete RPMI to $10^{10} / 1$. Aliquots were taken and plated $\left(1.5 \cdot 10^{5}\right.$ cells per well plate, culture volume $\left.200 \mu \mathrm{l}\right)$. Viability was $>95 \%$ (assessed by trypan blue exclusion). The cells were cultured at $37^{\circ} \mathrm{C}$ in a humidified air atmosphere for $96 \mathrm{~h}$ without (control) and with additives specified under Results. The culture was terminated on day 4 by addition of EDTA (final concentration $0.01 \mathrm{~mol} / \mathrm{l}$ ) and incubation overnight. The cells were resuspended and an aliquot was taken for cell counting according to the Coulter principle in a conductometric cell counter (Schärfe).

\section{Splenocyte activation}

The murine cells were stimulated either semiallogeneically or by concanavalin $A$. In semiallogeneic stimulation, $1 \cdot 10^{5}$ cells from spleens of the mother and their offspring (3 days old) were co-cultured (96 well culture plates). In concanavalin A stimulation $5 \mathrm{mg}$ of concanavalin A per litre of medium were used. After incubation for $24 \mathrm{~h}$, the supernatant was aspirated and replaced by medium containing prolactin in concentrations specified under Results (fig. 5).

\section{Bovine cells}

The bioactivity of prolactin forms was studied in bovine cell systems prepared from the reproductive organs and spleen of heifers (15). Materials in the cell preparation were from Serva when not otherwise stated.

Granulosa: Ovarian follicles (diameter of 2-4 mm) were aspirated with a syringe containing Dulbecco's phosphate buffered saline with $0.01 \mathrm{~mol} / \mathrm{l}$ EDTA. The cell aggregates were dispersed by pipetting, and the cells were centrifuged and resuspended in serum-free RPMI 1640-medium containing $0.01 \mathrm{~mol} / 1$ of EDTA and $20 \mathrm{mmol} / \mathrm{l} \mathrm{Hepes} \mathrm{(pH} \mathrm{7.3).}$

Oviductal epithelial cells: Excess connective tissue was trimmed from the oviducts, which were then washed in TCM 199 medium supplemented with fetal calf serum, (volume fraction 0.1 ) and flushed from the ampullary end towards the utero tubal junction with $10 \mathrm{ml}$ TCM 199-FCS medium. The flow-through was collected and centrifuged $(500 \mathrm{~g}, 10 \mathrm{~min})$. The cells were resuspended in serum-free RPMI 1640-medium.

Stromal cells: Endometrium samples were minced into Hank's balanced salt solution without divalent cations. After enzymatic removal of luminal epithelium the tissue was digested with trypsin and collagenase (16). The suspended cells were fractionated by gravity settling.

The stroma cells in the supernatant were centrifuged $(1000 \mathrm{~g}$, $5 \mathrm{~min}$ ), washed with Hank's balanced salt solution and re- 
suspended in RPMI 1640 medium supplemented with fetal calf serum (volume fraction 0.1$)$. The cells were plated $\left(50 \mathrm{~cm}^{2}\right.$ culture flasks) and grown as monolayers (5 days) changing the medium after 3 days. On the fifth day the cells were rinsed with Hank's balanced salt solution, trypsinized and subcultured in serum-free RPMI 1640 medium. The resulting stromal cell preparation contained more than $95 \%$ stromal cells, according to a vimentin assay (14).

Bovine splenocjtes:Spleens were stored in sodium phosphate $(0.01 \mathrm{~mol} / \mathrm{l})$-buffered saline $(\mathrm{pH} 7.4)$ on ice. The spleen was minced on a plastic screen, pore-size $45 \mu \mathrm{m}$. The erythrocytes were lysed $\left(7.8 \mathrm{~g} / \mathrm{l}\right.$ of $\left.\mathrm{NH}_{4} \mathrm{Cl}\right)$, and the remaining cells were washed in phosphate buffered saline $(500 \mathrm{~g}, 5 \mathrm{~min})$ and resuspended in RPMI 1640 medium supplemented with fetal calf serum, volume fraction 0.05 .

Cell culture: The cells were counted by a haemocytometer or conductometrically (Casy 1-cell analyser system, Schärfe). The viability was assessed by trypan blue exclusion (all preparations contained $>95 \%$ vital cells). The cells were grown in 96 well culture plates (Greiner) at a density of $2 \times 10^{5}$ cells per well using a volume of $50 \mu \mathrm{l}$ RPMI 1640 medium and $50 \mu \mathrm{l}$ RPMI 1640 medium supplemented with additives in the final concentrations specified in the figures. Controls contained only medium. Cells were incubated for 48 hours at $37^{\circ} \mathrm{C}$ in a humidified $\mathrm{CO}_{2}$-air mixture (1/20 volume $\mathrm{CO}_{2}$ ). Finally $250 \mathrm{pmol}$ of $\left[{ }^{3} \mathrm{H}\right]$ thymidine (Nuclear Research Institute, Rossendorf-Berlin) were added per well. After 18 hours the cells were harvested by a semiautomated harvestor (Skatron) on glass fibre disks (Whatman). The radioactivity was determined by liquid scintillation counting.

Modelling of alteration in circulating prolactin forms

Two breeds of cattle were used (Friesian and Galloway). The animals were trapped and bled via the $v$. jugularis (blood sample at $0 \mathrm{~min}$ ). Thyroliberin ( 4 or $8 \mu \mathrm{g} / \mathrm{kg}$ body weight) dissolved in physiological saline $(2 \mathrm{ml})$ was infused via the v. jugularis. After 15 and 60 minutes the bleeding was repeated. Thyroliberin was purchased from Sigma.

\section{Assays}

Prolactin was determined with commercially available ELISAkits (Milenia and Medgenix) or by densitometric quantitation of the electrophoretic and immunoblot bands with DESAGA equipment, calibrating the arbitrary units with commercial prolactin (Fluka) by electrophoretic and immunoblot analysis (7). The densitometric quantitation of the glycan moiety of the prolactins (detected with the glycan detection kit from Boehringer) was standardized with transferrin.

\section{Protein determination}

An aliquot $(20 \mu \mathrm{l})$ from either the sample to be determined or the standard solution containing $10,20,40$, or $80 \mathrm{mg} / \mathrm{l}$ of bovine serum albumin (Serva) or transferrin (Sigma) was added to 100 $\mu$ l Coomassie solution (50 mg of Coomassie G 250 were dissolved in $50 \mathrm{ml}$ methanol and diluted with $300 \mathrm{ml}$ distilled water, after addition of $50 \mathrm{ml} \mathrm{H}_{3} \mathrm{PO}_{4}(850 \mathrm{~g} / \mathrm{l})$ with vigorous shaking the solution was adjusted to $500 \mathrm{ml}$ with distilled water). Within $10 \mathrm{~min}$, the absorbance at $492 \mathrm{~nm}$ was recorded using a microplate reader (Behring).

\section{Antisera}

Rabbit anti-human prolactin antiserum was purchased (DAKO) or obtained by a standard rabbit immunization protocol utilizing purified human prolactin forms from amniotic fluid. In the proliferation studies and the immunoblot the antisera gave comparable results. Anti-prolactin antiserum and preimmune serum were purified by protein $A$ affinity chromatography using the standard protocol of the manufacturer (Pharmacia).

\section{Prolactin preparation}

Human amniotic fluid was collected from full-term deliveries and stored at $-20^{\circ} \mathrm{C}$. After thawing, centrifugation $(110000 \mathrm{~g}$, $20 \mathrm{~min}, 4^{\circ} \mathrm{C}$ ) and filtration to remove the lipids, glycinc was added $(0.25 \mathrm{~mol} / \mathrm{l})$, the $\mathrm{pH}$ was adjusted to 7.6 with ammonia and the solution was dialysed against $\mathrm{CH}_{3} \mathrm{CN}$ (final concentration $0.61-0.63 \mathrm{l} / \mathrm{l}$ dialysate) overnight at $4{ }^{\circ} \mathrm{C}$. The precipitates were removed by centrifugation $\left(6000 \mathrm{~g}, 10 \mathrm{~min}, 4^{\circ} \mathrm{C}\right)$, urea was added $(2 \mathrm{~mol} / \mathrm{l})$ and the organic phase was evaporated in vacuo. Following the addition of $\mathrm{NH}_{4} \mathrm{HCO}_{3}(0.08 \mathrm{~mol} / \mathrm{l}, \mathrm{pH} 8)$, anion exchange chromatography was performed (1 volume of DEAE A25 (Pharmacia) equilibrated in $100 \mathrm{mmol} / 1 \mathrm{NH}_{4} \mathrm{HCO}_{3}$. pH 8 , per 8 volumes of evaporated fluid), the flow-through was collected, glycine was added $(0.1 \mathrm{~mol} / \mathrm{l})$ and portions of $1 \mathrm{ml}$ were lyophilized. The product was fractionated by concanavalin A Sepharose 4B (Pharmacia) affinity chromatography using $2 \mathrm{ml}$ gel per column. The lyophilized product (total protein $80-100 \mu \mathrm{g}$ ) was dissolved in $1 \mathrm{ml}$ of distilled water and dialyzed against 50 volumes binding buffer $(0.1 \mathrm{~mol} / \mathrm{l}$ Tris- $\mathrm{HCl}, \mathrm{pH} 7.5$, $0.3 \mathrm{~mol} / 1 \mathrm{NaCl}, 0.005 \mathrm{~mol} / 1 \mathrm{MgCl}_{2}$ ) overnight at $4{ }^{\circ} \mathrm{C}$. After rinsing of the gel with binding buffer $(8 \mathrm{ml})$, the column was loaded, then washed with binding buffer at a flow rate of 1.8 $\mathrm{ml} / \mathrm{h}$ until the absorbance at $280 \mathrm{~nm}$ (recorded by a Uvicord and Alphaplot (LKB)), was nearly zero. The retained material was eluted with $0.2 \mathrm{~mol} / \mathrm{l}$ methyl- $\alpha-D$-glucoside in binding buffer.

\section{Electrophoresis and western blot}

Samples were electrophoresed under non-reducing conditions using polyacrylamide gels in the presence of sodium dodecyl sulphate and stained as described (7). In the analysis of the cicrulating prolactin forms, the serum (1 volume) was diluted with 15 volumes of $0.125 \mathrm{~mol} / 1$ Tris- $\mathrm{HCl}, \mathrm{pH} 6.8$, supplemented with $1 \mathrm{~g} / \mathrm{l}$ sodium dodecyl sulphate.

The blot was performed with nitrocellulose sheets (Schleicher \& Schüll, $0.45 \mu \mathrm{m}$ pore size): the gels were placed on 3 filter papers soaked with cathode buffer $(0.04 \mathrm{~mol} / \mathrm{l}$ 6-aminohexanoic acid, $200 \mathrm{ml} / \mathrm{l}$ methanol) then covered with the nitrocellulose, followed by a single filter paper (previously soaked in anode buffer: $0.015 \mathrm{~mol} / 1$ Tris, $200 \mathrm{ml} / \mathrm{l}$ methanol), which was pressed on top. The next 2 filters were soaked in $0.3 \mathrm{~mol} / \mathrm{l}$ Tris, 200 $\mathrm{ml} / \mathrm{l}$ methanol. After the electrotransfer $\left(1 \mathrm{~mA} / \mathrm{cm}^{2}, 1 \mathrm{~h}\right)$, the nitrocellulose was blocked with $0.3 \mathrm{~g} / \mathrm{l}$ Gelafusal (Serumwerk Bernburg) in $0.05 \mathrm{~mol} / 1$ Tris- $\mathrm{HCl}, 0.2 \mathrm{~mol} / 1 \mathrm{NaCl}, \mathrm{pH} 7.4$ (Tris buffered saline) and stained either by the immunotechnique (7) using rabbit antiprolactin antiserum (DAKO) diluted $1: 200$ with Tris buffered saline- $0.1 \mathrm{~g} / \mathrm{l}$ Gelafusal, and antirabbit peroxidase-conjugated biotin-avidin antibody system from Vektor Laboratories, or with the glycan detection kit (Boehringer).

\section{Statistical analysis}

Differences were compared between the control group mean and a test group mean in each case. Three experiments ivere performed (when not otherwise stated), in which the variants were run in triplicate. The significance of differences was determined by Student's t-test, using the modification of CochranCox for unequal variances. This was judged by the F-test in the analysis of variances. An error probability of $P<0.05$ for the theoretical $t$-values was used. The results are reported as $\mathrm{M}$ (mean) and SD (standard deviation) or SEM (standard crror of the mean). 


\section{Results}

Different amniotic fluids contain different patterns of prolactins

The prolactin patterns of 6 individual amniotic fluids were examined by electrophoresis (fig. 1). All electropherograms indicated a band of $M_{\mathrm{r}} 29000$. In 5 pherograms, bands of $M_{\mathrm{r}} 28000,60000$ and 64000 were observed. Four pherograms displayed bands of $M_{\mathrm{r}}$ 24000 , 39000-41000, while 3 pherograms also showed bands of $M_{\mathrm{r}} 14500,20000,25000,27000$, 87000,117000 , and 125000 . A band of $M_{\mathrm{r}} 140000$ was detected in 2 cases.

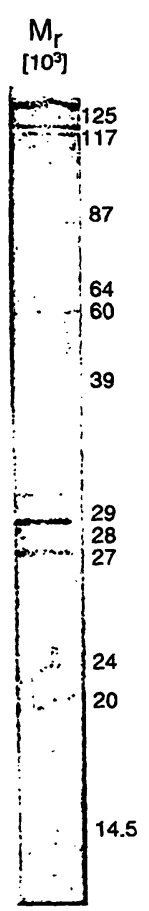

1

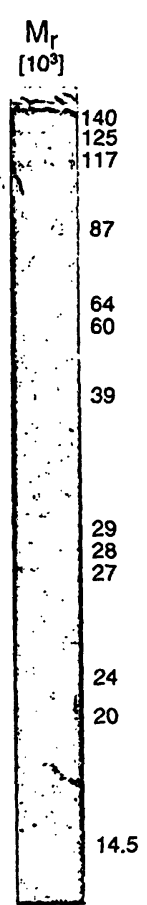

2

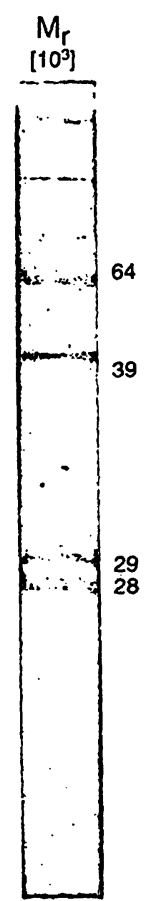

3

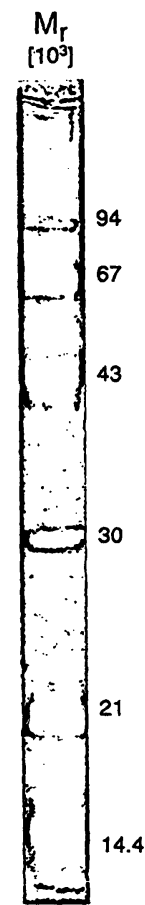

4
All these bands were immunoreactive, as illustrated by the analysis of amniotic fluid number 1 (fig. 3). However, as this fluid did not reveal the $M_{\mathrm{r}} 20000$, $M_{\text {r }} 39000-41000$ and high-molecular mass forms, these immunoreactive bands are not shown. Figure 1 demonstrates further, that the processing procedure and the electrophoretic analysis provide highly reproducible results. Only in the region of $M_{\mathrm{r}} 125000-$ 140000 and in the double band of $M_{\mathrm{r}} 28000$ did the repeated experiment give an ambigous result.

Different forms of prolactin separated from amniotic fluid by concanavalin A-Sepharose chromatography are not adequately detected by the usual immunoassays

Concanavalin A-Sepharose affinity chromatography was employed to separate the prolactins of amniotic fluid in order to examine whether defined forms differ in immuno- and bioassays. Figure 2 depicts the profile of an amniotic fluid product separated by chromatography, with absorbance recorded at $280 \mathrm{~nm}$. The profile shows two peaks of which the first is shouldered. The first peak emerges by washing the column with binding buffer, the second during elution with methyl- $\alpha-D$-glycoside. After loading $80 \mu \mathrm{g}$ of total protein, the first peak yielded $46.4 \mu \mathrm{g}$ and the second yielded $5.8 \mu \mathrm{g}$ protein, of which only $2-3 \mu \mathrm{g}$ and $3-5 \mathrm{ng}$, respectively, were identified as prolactin by commercial immunoassay kits. This type of chromatogram profile was highly reproducible for any given amniotic fluid. However, in 2 of the 6 amniotic fluids, separation of the first shouldered peak was almost complete (data not shown).

Fig. 1. Silver stained electropherograms of prolactin patterns from amniotic fluid, and of prolactins bound to Concanavalin ASepharose.

The volume of the amniotic fluid was $200 \mathrm{ml}$ in each case. Half of this was used for repeating the preparation procedure and electrophoretic analysis of the product under non-reducing conditions (12.5\% SDS-PAGE). The gel was loaded with $5 \mu \mathrm{g}$ of total protein in each case, except lane $3(1 \mu \mathrm{g})$. Lanes 1 and 2 depict the bands of the repeated experiment using the preparation 5 . Lane 3 shows the band pattern from prolactins bound to Concanavalin A-Sepharose. Lane 4 contains molecular mass markers.

Comparison of 1 with 2 indicates that the repeated preparation and electrophoretic procedure provide almost identical results (the SEM of the estimated relative molecular masses in triplicate experiments were $M_{\mathrm{r}} 500-1000$ ). Bands probably corresponding to prolactin forms are listed below in order of their relative molecular masses, for each of the 6 investigated samples of amniotic fluid:

Sample Relative molecular mass of the band $\left[10^{3}\right]$

no.

\begin{tabular}{rlllllllllllllll}
\hline 1 & 14.5 & $16 \mathrm{~d}$ & & 24 & 25 & 27 & & 29 & & 60 & 64 & & \\
2 & & & & & & & $28 \mathrm{~d}$ & 29 & $39-41$ & & & 87 &. & \\
3 & 14.5 & & 20 & 24 & 25 & 27 & 28 & 29 & $39-41$ & 60 & 64 & 87 & \\
4 & & & 20 & & & & 28 & 29 & & 60 & 64 & 87 & 117 & 125 & \\
5 & 14.5 & 16 & & 24 & & & $28 \mathrm{~d}$ & 29 & $39-41$ & 60 & 64 & & $117 \mathrm{~d}$ & 125 & 140 \\
6 & & & 20 & 24 & 25 & 27 & 28 & 29 & $39-41$ & 60 & 64 & & $117 \mathrm{~d}$ & 125 & $(140)$ \\
\hline
\end{tabular}

All $M_{\mathrm{r}}$-values shown on the figure and in the table have been multiplied by $10^{-3}$. The band corresponding to $M_{\mathrm{r}} 140 \times 10^{3}$ in preparation 6 was absent in the repeated analysis; $d$ indicates the presence of a double band, which was not further defined. 
Concanavalin A-Sepharose chromatography provides highly purified glycosylated prolactins

The electrophoretic patterns of the material from both peaks obtained by concanavalin A-Sepharose affinity chromatography were developed by Coomassie and silver staining (fig. $3 a$ and $b$ ) to demonstrate not only the reproducibility but also differences in the stain intensity. Silver staining involves oxidizable hydroxyl groups, so that highly glycosylated proteins may be more intensively stained by the silver stain procedure than by Coomassie dye binding. Direct glycan detection revealed significant quantities of glycan in the $M_{\mathrm{r}} 60000-64000$ region. Varying amounts of glycan were observed in the $M_{\mathrm{r}} 25000-29000$ bands, with an intensity similar to that of the transferrin band containing $58 \mu \mathrm{g}$ glycan moiety per $\mathrm{mg}$ protein. Especially the $M_{\mathrm{r}} 60000-64000$ prolactins were obviously more intensively stained by direct glycan detection and silver staining than by Coomassie dye binding.

Using equal quantities of total protein, the direct glycan detection of immunoreactive bands (fig. 3c) on blotted gels (fig. 3d) was only weakly correlated with the degree of staining.

The proteins from the second composite peak were almost complete immunoreactive, whereas the densitometric analysis of both fractions of the first shouldered peak indicated that $74-83 \%$ of the stain density corresponded to prolactin forms (data not shown). Despite the purification potential of the concanavalin A-Sepharose chromatography for glycosylated forms per se, more than one peak contains several overlapping forms of similar molecular mass and degree of glycosylation. That they are only moderately separable (indicated by the distribution of the molecular masses described in fig. 2) suggests dissimilarities in their glycan structure.

\section{Hypothalamic activity alters the circulating prolactin pattern}

An animal model was used to demonstrate that the prolactin forms do not vary randomly, but the pattern may correspond to hypothalamic activity. Two behaviourly different breeds of cattle were exposed to thyroliberin. The behaviour of the two animal groups was distinguished by the flight-fight syndrome (17) under bleeding. stress (fig. 4). If the prolactin pattern is in any way dependent on the physiological situation and especially on hypothalamic activity induced by stress, the different circulating prolactin forms are to be expected in behaviourly different groups after chal- lange by hypothalamic neurohormones. Figure 4 shows this to be the case. Both behavioural groups differed in the sensitivity to the bleeding stress and to the neurohormone. Contrasting to the control animals

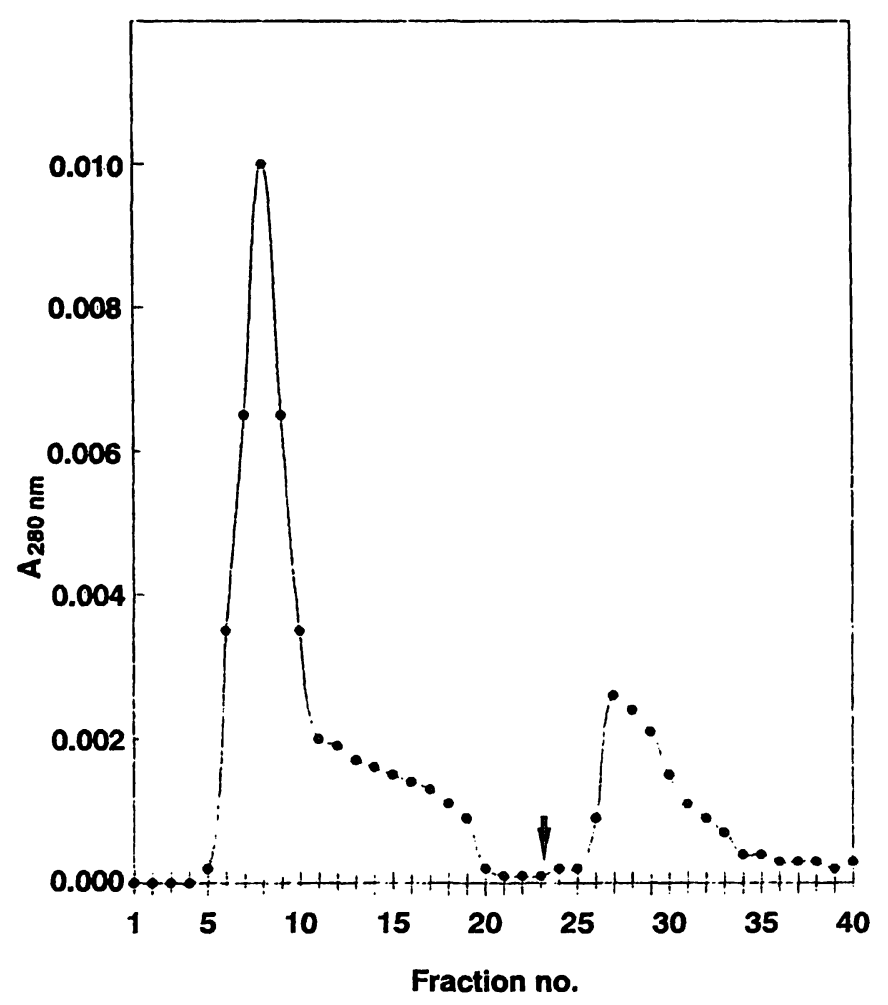

Fig. 2. Concanavalin A affinity chromatogram profile. Absorbance of the effluent was recorded at $280 \mathrm{~nm}$. After loading with prolactin-containing solution dialyzed against binding buffer, the column was washed with binding buffer.

The arrow indicates the start of the elution with methyl$\alpha$-D-glucoside, with the ultraviolet absorbance amplified 10 -fold. Pooled fractions $6-20$ of peak 1 had a volume of $5.6 \mathrm{ml}$ and an absorbance at $280 \mathrm{~nm}$ of 0.004 . Pooled fractions $26-36$ of peak 2 amounted $4 \mathrm{ml}$ with an absorbance at $280 \mathrm{~nm}$ of 0.0006 .

Preliminary experiments using glycosylated and nonglycosylated proteins (transferrin and bovine serum albumin) as standards, and comparing the results of the protein determination (protein dye-binding and ultraviolet absorbance) showed that $1 \mathrm{~g} / \mathrm{l}$ of the almost pure prolactin obtained in peak 2 has an absorbance at 280 $\mathrm{nm}$ of 0.5 . Using this result, the pooled fractions contained 46.4 and $5.8 \mu \mathrm{g}$ respectively. The solution loaded onto the column contained $80 \mu \mathrm{g}$ of protein determined by Coomassie dye binding. Thus, the protein recovery was $66 \%$ for the chosen fractions, but $87 \%$ based on all fractions.

The proteins of peaks 1 and 2 were electrophoresed under non-reducing conditions; the following bands were identified as prolactins by immunoblot: in peak 1 , $M_{\text {r }} 14500-16000,20000,27000,29000,117000-$ 140000 ; in the shoulder of peak 1 (fractions 12-20), $M_{\text {r }} 14500-16000,24000-25000,28000-29000$, 60000-64000, 87000,117000-140000; in peak $2 M_{r}$ $27000-29000,39000-41000,60000-64000,87000$. Densitometric quantitation revealed $74-83 \%$ of the proteins in peak 1 were prolactins. The peak 2 forms were virtually uncontaminated with other proteins. Commercial kits detected only $1 / 10$ and $1 / 1000$ of the prolactin identified by immunoblot in peaks 1 and 2 , respectively. 

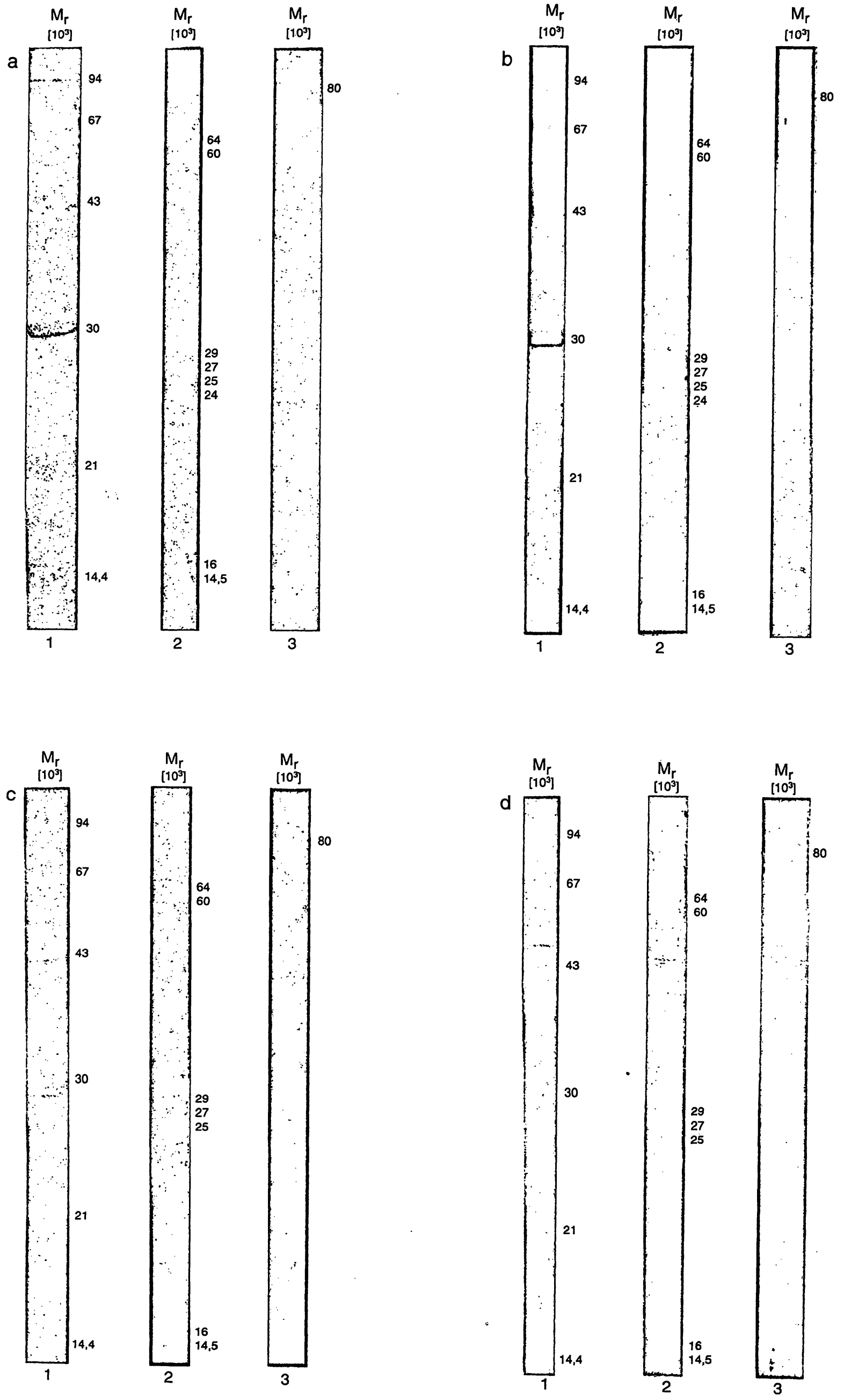

Eur. J. Clin. Chem. Clin. Biochem. / Vol. 31, 1993 / No. 12 
of the flight type group the control of the fight type group reacted to the repeated bleeding stress with an increase in the prolactin forms. In the flight types at the start of the experiment (frequency of the forms at $0 \mathrm{~min}$ ) the animals intended to respond to thyroliberin and the control revealed differences. Despite this individual variability they responded to the neurohormone with an increase in the forms with $M_{\mathrm{r}}<30000$ but later (at $60 \mathrm{~min}$ ) than the fight types. These animals with violent defence reacted already $15 \mathrm{~min}$ after the thyroliberin infusion with the expression of two additional prolactins of $M_{\mathrm{r}}<30000$ (the corresponding means at 0 and $15 \mathrm{~min}$ were $2.5 \pm 0.5$ versus $4 \pm 1$ ). The thyroliberin effect on the number of the prolactin forms was dose-dependent, after dose of $4 \mu \mathrm{g} / \mathrm{kg}$ body weight the prolactin pattern showed only a slight tendency to alter (data not shown), whereas $8 \mu \mathrm{g} / \mathrm{kg}$ body weight caused the change depicted in figure 4.

The bioactivity of the concanavalin A-Sepharose bound prolactins depends on the cell types used as targets

The dose-response to glycosylated prolactins contained in peak 2 of the concanavalin A-Sepharose affinity chromatography was compared with that of standard prolactin of $M_{\mathrm{r}} 20000$ (electrophorized under non-reducing conditions) from the commercially available prolactin assay kit, using murine splenocytes activated by concanavalin A (fig. 5a) and activated semiallogeneically (fig. 5b). Proliferation of spleen cells was enhanced (estimated indirectly by $\left[{ }^{3} \mathrm{H}\right]$ thymidine incorporation) in the presence of glycosylated prolactins, independently of the method of activation. The stimulatory effect was dose-dependent. A low prolactin level of $2.5 \mu \mathrm{g} / \mathrm{l}$ increased the proliferation rate (fig. 5a) almost two-fold compared

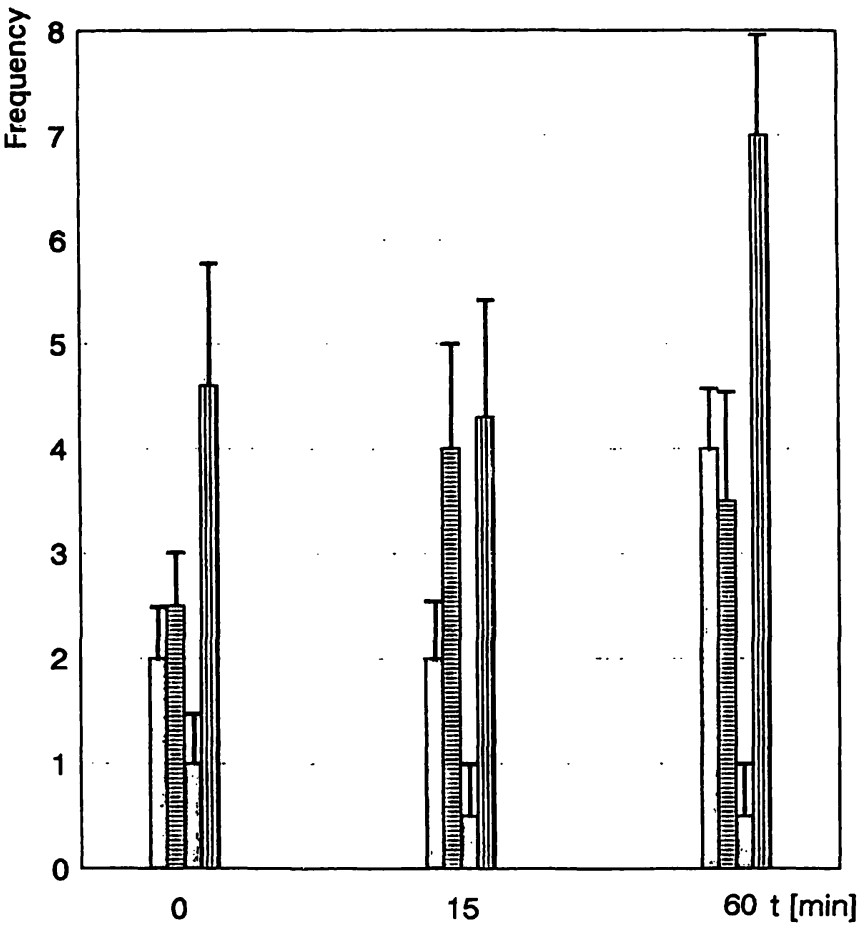

Fig. 4. Alteration in the number of circulating prolactin forms by the hypothalamic neurohormone, thyroliberin.

To investigate the proposal that relation between hypothalamic activity and prolactin response in stress is specified by a certain physiological situation defined by the behaviour, two breeds of cattle (Galloway and Friesian) were used to model differences in the production of prolactins. The two groups were distinguished by the flight-fight syndrome under stress. Two and four animals (control and treatment groups, respectively) of the Galloway (bars 1 and 2 from a bar group) and Friesian (bars 3 and 4 from a bar group) were used.

The Galloways, with their violent defence behaviour, tried to overcome the venipuncture stress through butting and kicking whereas the Frisians tried to escape the blood drawing stress through flight despite being trapped. The treatment group received thyroliberin $(8 \mu \mathrm{g} / \mathrm{kg})$ in physiological saline, the control group physiological saline $(2 \mathrm{ml})$. The bars indicate the number (mean of the group) of bands (frequency) that stained positively in the immunoblot at the start of infusion (0 minutes) and after the infusion (15 and 60 minutes) in the range of $M_{\mathrm{r}} 14500-30000$. The small bars represent SD.

Fig. 3. Profiles of gels visualized by Coomassie dye binding (a), silver staining (b), immunoblot (c), and glycan detection blot (d).

Electrophoresis was performed in sodium dodecyl sulphate polyacrylamide gels $(12.5 \%)$. Each well was loaded with $3 \mu \mathrm{g}$ protein, using preparation number 1 . listed in figure 1 .

The Coomassie-stained lanes of panel a represent

3: transferrin $(2 \mu \mathrm{g})$, used as a standard glycosylated protein, $M_{\mathrm{r}} 80000$, with a glycan content of $58 \mathrm{~g} / \mathrm{kg}$ protein.

2: bands of $M_{\mathrm{r}} 14500,16000,24000,25000,27000,29000$ and 64000 ,

1: molecular mass standards of $M_{\mathrm{r}} 94000,67000,43000,30000,20100$ and 14400.

The silver-stained lanes (panel b) represent

1: molecular mass standards as described.

2: bands of $M_{\mathrm{r}} 14500,16000,24000,25000,27000,29000,60000$ and 64000.

3: transferrin.

The immunoblot (panel c) revealed bands of $M_{\mathrm{r}} 16000,25000,27000,29000$ and $60000-64000$ in lane 2. Lane 1 contains the marker proteins (rainbow standards, Pharmacia). Transferrin was loaded as a negative control in lane 3 . Polyclonal rabbit antihuman prolactin antiserum (DAKO) and antirabbit peroxidase-conjugated biotin-avidin antibody system (Vector Laboratories) were used in the immunoblot.

The glycan detection (panel d) indicates that the $M_{\mathrm{r}} 60000-64000$ material was heavily stained whereas the bands of $16000,25000,27000$ and 29000 were weakly stained. Lane 3 shows the staining of transferrin used as positive control. The glycan moiety per blotted band was determined with the glycan detection kit (Boehringer). 

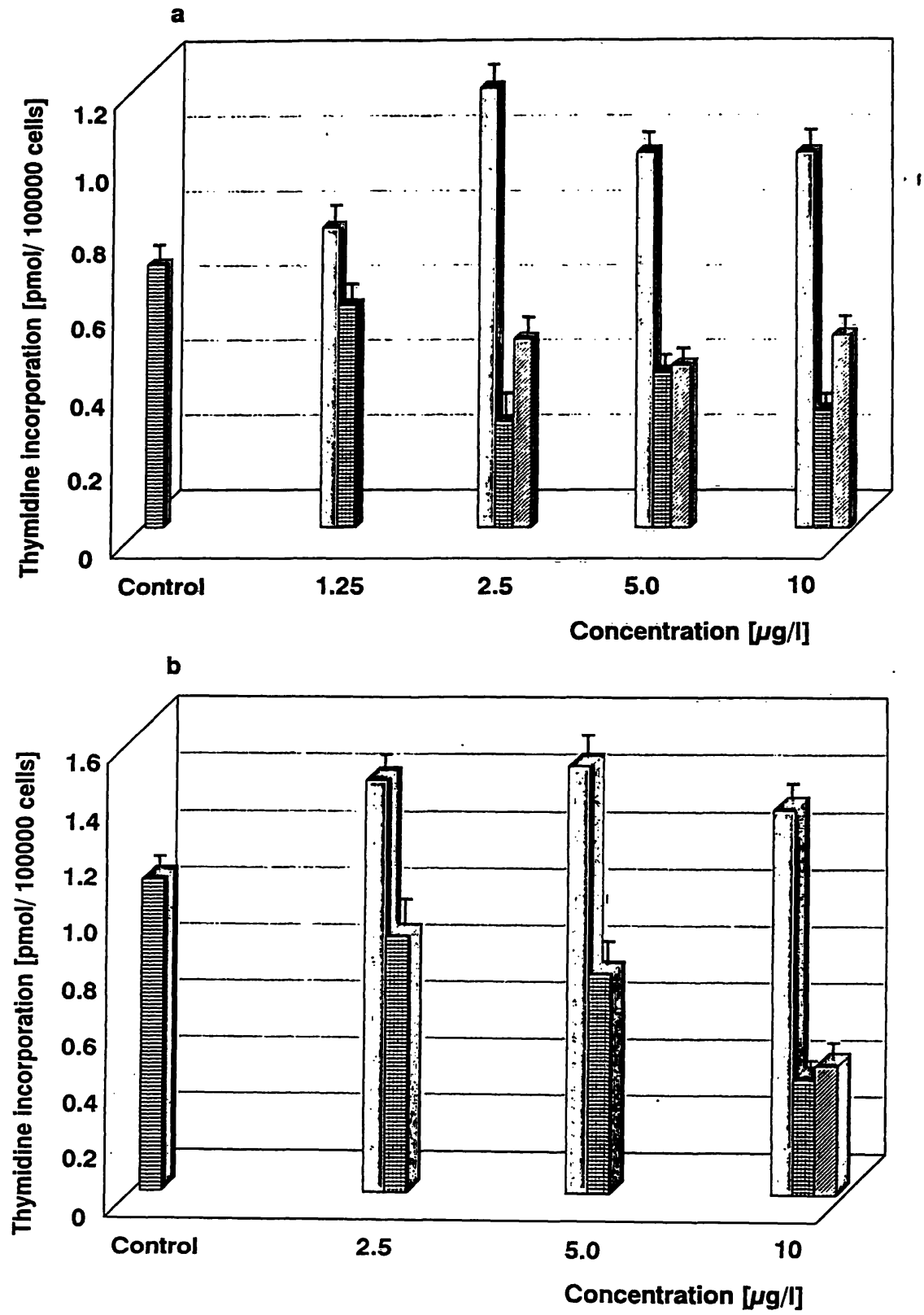

Fig. 5. Opposite effects of non-glycosylated and glycosylated prolactin forms on the proliferation of concanavalin A-stimulated (a) and semiallogeneically stimulated (b) spleen cells from mice.

Splenocytes from mice $\left(1.5 \cdot 10^{5}\right.$ per well of a 96 -culture plate) were activated by concanavalin A $(5 \mathrm{mg} / \mathrm{l})$ or by mixing the maternal cells $\left(1 \cdot 10^{5}\right)$ with splenocytes $\left(1 \cdot 10^{5}\right)$ from offspring aged 3 days (semiallogeneic stimulation). The cells were incubated for 5 days without (control), and with prolactin standard non-glycosylated forms of $M_{\mathrm{r}} 20000$ or 23000 from a commercially available prolactin assay kit, or with glycosylated prolactins bound to concanavalin A-Sepharose which are defined in figure 1 . The prolactin concentrations and the $\left[{ }^{3} \mathrm{H}\right]$ thymidine incorporation are given on the abscissa and ordinate, respectively. The stimulatory activity was reversed by antiprolactin antiserum (DAKO) using $1 \mathrm{mg}$ of the purified immunoglobins per litre of the culture medium (data not shown). Addition of glycosylated prolactins compensated partly the inhibitory activity of non-glycosylated prolactins. The compensation effect was statistically significant. The bars represent the means, and the small bars mark the SEM. The experiments were run in duplicate with 3 repeats per variant.

with the control (stimulation without prolactin). The stimulatory baseline (control) was higher in the semiallogeneic experiment, but the relative stimulation by prolactin was smaller (fig. $5 b$ ).

To assess the specifity of the effect, purified antiprolactin antiserum was added and this reversed the proliferative activity whereas the preimmune serum was not active (data not shown). Proliferation of splenocytes, which had been activated semiallogeneically (fig. 5b) or by concanavalin A (fig. 5a), was inhibited significantly and in a dose-dependent manner by standard prolactin. Addition of glycosylated prolactins to the culture medium decreased this inhibition of proliferation by standard prolactin. The difference $(0.4 \pm 0.03$ pmol versus $0.5 \pm 0.02 \mathrm{pmol}$ thymidine incorporation in the presence of standard prolactin and both prolactin forms, respectively) was statistically significant.

Bovine cells were used to study the bioactivity of the prolactins that did not bind to concanavalin A-Se- 
pharose (unbound prolactin fraction), or were retarded in their migration through a concanavalin ASepharose column (retarded prolactin fraction). These fractions were available in sufficient amounts for dose-dependent triplicate experiments (fig. 6).

Thymidine incorporation into bovine spleen cells was markedly increased (3.5-4 times the control) in the presence of unbound prolactin fraction $(2 \mu \mathrm{g} / 1)$, this stimulation decreased with increasing unbound prolactin fraction concentration, but was still apparent at $16 \mu \mathrm{g} / \mathrm{l}$ (about twice the control). In contrast, unbound prolactin fraction was no longer stimulatory at $16 \mu \mathrm{g} / \mathrm{l}$ (fig. 6a).

Bovine granulosa cells responded in dose-dependent fashion to retarded prolactin fraction with a significant increase of thymidine incorporation at low concentration $(2 \mu \mathrm{g} / \mathrm{l})$ and a significant inhibition at 16 $\mu \mathrm{g} / \mathrm{l}$, whereas the unbound prolactin fraction stimulated in the concentration range $2-16 \mu \mathrm{g} / \mathrm{l}$ (fig. $6 \mathrm{~b}$ ). Thymidine incorporation into bovine oviduct epithelial cells showed a constant stimulation (about 1.6 times the control) for all unbound prolactin fraction concentrations between 2 and $16 \mu \mathrm{g} / \mathrm{l}$, whereas the stimulation by retarded prolactin fraction decreased with increasing concentration, becoming constant (about 1.2 times the control) at 8 and $16 \mu \mathrm{g} / \mathrm{l}$ (fig. 6c). Highly purified stromal cells from the endometrium responded to retarded prolactin fraction dosedependently, showing maximal stimulation at $4 \mu \mathrm{g} / \mathrm{l}$ whereas unbound prolactin fraction stimulated the thymidine incorporation markedly $(2-2.5$ times the control) at all concentrations examined (fig. 6d).

\section{Discussion}

Although the molecular heterogeneity of prolactin in amniotic fluid has been described $(1,2)$ there appear to be no reports on the variability between individual fluids from full-term deliveries. In the present study we found considerable differences in the prolactin patterns of individual amniotic fluid samples, and only one form of prolactin $\left(M_{\mathrm{r}} 29000\right)$ was present in all 6 specimens studied. Surprisingly, the prolactins of $M_{\mathrm{r}} 20000$ or 23000 , defined as pure non-glycosylated prolactin $(1,3)$ were detected only in 3 cases, whereas the forms of $M_{\mathrm{r}} 14500,24000,27000$, $39000-41000,60000-64000,87000$, and $117000-$ 125000 were more frequent. Except for the prolactins of $M_{\mathrm{r}} 60000-64000$, which were evident as a double band in electrophoresis as well as in immunoblotting or in the glycan detection blot, most of the other prolactin forms were also found in human serum (1, 8) or follicular fluid (9), and in rat pituitary extracts, rat pituitary cell aggregate cultures (5) or rat blood plasma (10). The $M_{\mathrm{r}} 22000$ prolactin form is defined in rat as unglycosylated monomer (10), whereas in the human the $M_{\mathrm{r}} 20000$ or 23000 band under nonreducing or reducing conditions is attributed to pure prolactin (1). Thus exact comparability of prolactin patterns is restricted to intraspecies studies. Recently it has been reported (1) that the $M_{\mathrm{r}} 64000$ form was evident in human amniotic fluid only under reducing conditions (using $\beta$-mercaptoethanol as reducing agent). After processing the amniotic fluid with an organic phase and urea, this form is also detectable under non-reducing conditions, as presented here. Moreover, reducing conditions in the electrophoresis did not alter this highly glycosylated prolactin form or any other forms of $M_{\mathrm{r}}<100000$. However, dialysis against glycine or bicarbonate buffer, $\mathrm{pH}$ 9.510 (with ammonia) at $6^{\circ} \mathrm{C}$ for 24 hours, causes the $M_{\mathrm{r}}$ 25000-29000 forms to disappear, whereas the forms of $M_{\mathrm{r}}$ 20000-23000 remain (unpublished data). The use of such $\mathrm{pH}$ values in the extraction of prolactin from pituitary in standard procedures for prolactin preparation may therefore produce artefacts.

In vivo, the forms of $M_{\mathrm{r}} 20000$ or 23000 (detected under reducing conditions) are evident in serum after administration of thyroliberin but nearly absent in eu- and hyperprolactinaemia without thyroliberin treatment (1). In contrast, the form of $M_{\mathrm{r}} 14500$ persists in hyperprolactinaemia and is absent in normoprolactinaemia but can be induced by thyroliberin (1). Moreover, such thyroliberin-induced circulating prolactins appear to decay more slowly (19).

Reported investigations of hypothalamic-mediated alterations in circulating prolactin forms appear to be limited to the effects of thyroliberin, with no consideration of the individual behavioural response to emotional stimuli. We therefore used two behaviourally different breeds of cattle to monitor the effect of stress on the pattern of prolactin production. The results demonstrate striking differences in the number of prolactin forms between the behavioural groups. Moreover, following stress, the number of different molecular mass forms varies with time, and the temporal response of this prolactin pattern is affected differently by thyroliberin, depending on the behavioural breed.

It is not known whether stress-mediated thyroliberin secretion alters the amniotic fluid prolactin pattern. However, as most prolactin forms are found in both amniotic fluid and serum, one is tempted to speculate that the different individual prolactin patterns reported here are due, at least in part, to the stress intensity and the stress susceptibility at birth. 

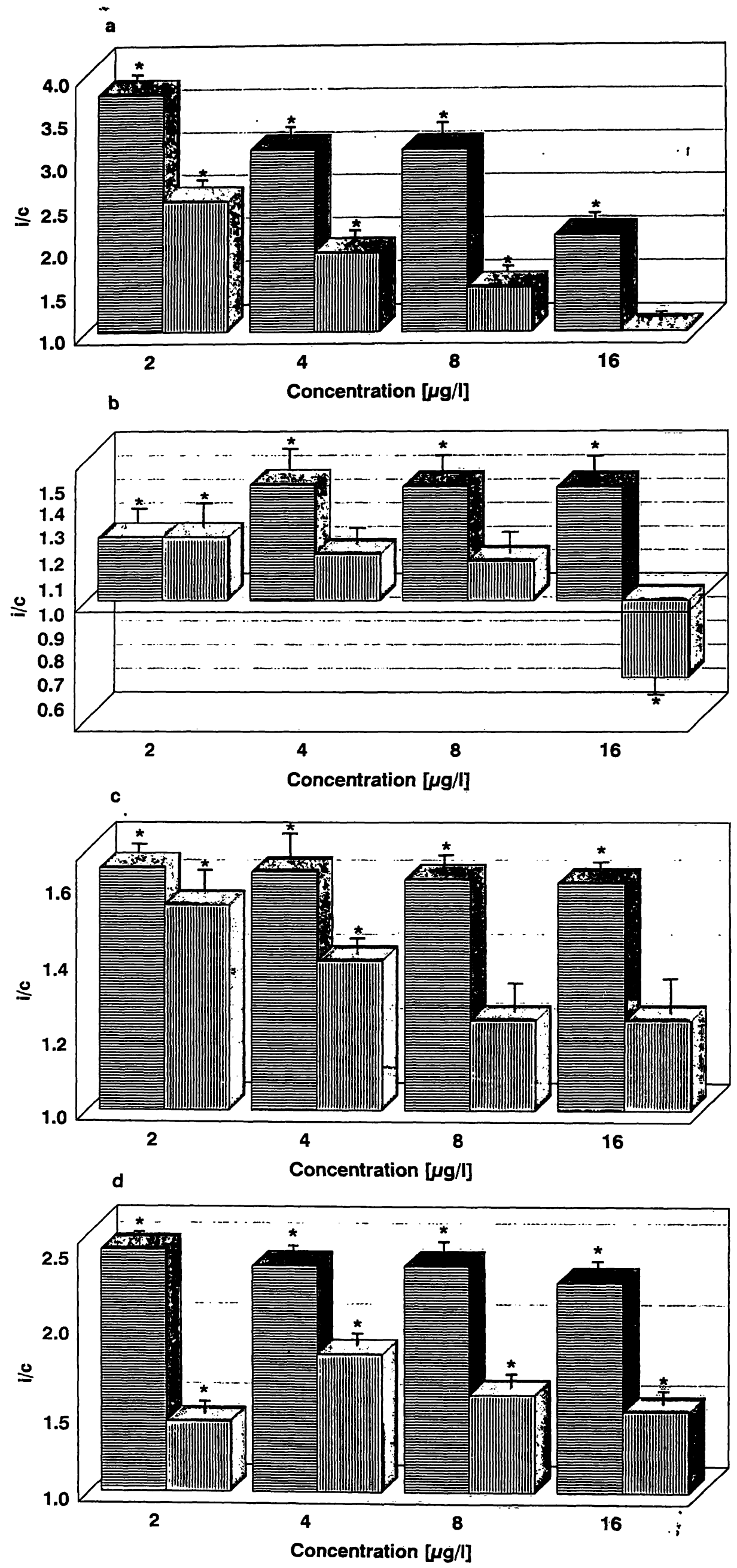

Eur. J. Clin. Chem. Clin. Biochem. / Vol. 31, 1993 / No. 12 
The lack of a constant prolactin pattern complicates the problem of detection. An attempt was made to exploit the affinity of glycosylated prolactins to concanavalin A-Sepharose, to obtain defined forms of the hormone. The affinity chromatography actually separated the different forms, but with only moderate efficiency. The failure of some glycosylated forms to bind to concanavalin A-Sepharose has been reported (3), using a prolactin source other than amniotic fluid. In two of the six amniotic fluids, two well resolved peaks were obtained in both the washing and elution procedures. The prolactin-enriched material from the other amniotic fluids was separated as shouldered peaks. The second peak of the first dimer or the shoulder of the first peak is probably due to weak interactions between the glycan moiety of the prolactins and the concanavalin A groups of the Sepharose, since the direct glycan detection of the blotted forms revealed that they are glycosylated. Quantitation of the degree of glycosylation was difficult because of technical difficulties in the use of the kit, but the glycan moiety of the forms of $M_{\mathrm{r}} 25000-29000$ appears to be smaller than that of transferrin $(58 \mu \mathrm{g}$ glycan groups per mg protein) while the forms of $M_{\mathrm{r}}$ 60000-64000 are much more highly glycosylated than transferrin.

It was recently reported that the glycosylation heterogeneity of prolactin affects the diagnostic accuracy of prolactin determinations (4). As demonstrated here, only about $1 / 10$ of the prolactin forms of the first peak from the concanavalin A-Sepharose chromatogram were monitored by commercial prolactin kits, although $74-83 \%$ of the proteins consisted of prolactin, according to the immunoblot. The pure prolactin forms from the second dimer were virtually undetected.

This brings into question the definition of dys- or normoprolactinaemia by commonly used immunoassays. However, whether accurate measurement of the different forms of prolactin is necessary depends on the biological significance of glycosylation. To approach this question, glycosylated prolactins of high purity were examined in spleen cells activated by concanavalin $\mathrm{A}$ or by semiallogeneic interaction, i.e. in a system which may be relevant to the in vivo situation. To investigate possible channelling of circulating forms to target cells by glycosylation we also studied the bioactivity of prolactins in various model physiological situations, using cells from the bovine reproductive tract and spleen. Despite the considerable work reported on the effects of prolactin on cells from the reproductive tract or spleen, information on the bioactivity of different forms of prolactin is not available.

However, it is known that human and rat endometrial stromal cells produce prolactin in response to progestins (11). Rat placenta (20) or decidua (26) and human myometrial explants (12) synthesize molecular forms of $M_{\mathrm{r}} 23000,27000$ and 29000 . Human amniotic fluid prolactin is presumably derived from this source (13). In an autocrine or paracrine manner, the endometrial stromal cells not only produce prolactin but also begin to proliferate and differentiate into decidual cells in response to prolactin (14) during the early stage of pregnancy. Our bovine and murine cell models showed that concanavalin A-fractionated prolactins exert dose-dependent, different or opposite effects on bovine cells from the reproductive tract (endometrial stroma, oviduct, granulosa) and on bovine or murine splenocytes. The murine spleen cells were semiallogeneically activated to reproduce the possible situation in vivo during implantation and haemochorial placentation, in which the semiallogeneic trophoblast evades destruction by the mother's immune system despite the intimate contact with the maternal blood. According to the presented results, the proliferation of activated splenocytes is inhibited by nonglycosylated prolactin forms but enhanced by certain glycosylated forms from amniotic fluid, suggesting that the balance of these two prolactin forms is part of an immune-endocrine mechanism in the feto-placental unit for maintaining pregnancy. Displacement experiments (4) show that despite different affinities the prolactin forms are bound to prolactin receptors. Thus, different forms of circulating prolactin can compete for a binding sites, thereby signalling an altered physiological situation.

The existence of different forms of prolactin with specialized roles is not without precedent. The structural form of the prolactin molecule available to the

Fig. 6. The bioactivity of prolactin forms in bovine cells:

(a) splenocytes, (b) ovarian granulosa, (c) epithelial cells from the oviduct, (d) stromal cells from the endometrium.

The bars represent the effects of the prolactins that did not bind to concanavalin A-Sepharose, corresponding to fractions 6-11 in figure 2 (first bar from a bar group), and the effects of prolactins that were retarded on the concanavalin Acolumn, corresponding to fractions $12-20$ in figure 2 (second bar from a bar group). The rate of the $\left[{ }^{3} \mathrm{H}\right] \mathrm{thymidine}$ incorporation for each prolactin concentration (i) is given in relation to the control $\mathrm{c}(\mathrm{i} / \mathrm{c})$. The small bars represent the standard deviations. An asterisk marks significant difference from the control. The experiments werc run in triplicate with triplicate repeats per concentration variant. 
target tissue may be crucial for the normal function of the tissue, as suggested by experiments on the effects of glycosylated and non-glycosylated prolactins on islet cell division and insulin secretion in homologous and heterologous systems $(22,23)$. Moreover, it has been reported that thymidine incorporation into gonadotrophs and thyrotrophs, but not other pituitary cell types, is increased by prolactin of $M_{\mathrm{r}} 16000$, whereas the main forms were inactive (5).

Bioactivity of prolactin is modified not only by glycosylation, cleavage or aggregation but also by phosphorylation (21). Cell division of pituitary tumour cells was promoted only by dephosphorylated prolactin $\left(M_{\mathrm{r}} 24000\right)$, whereas phosphorylated forms may exert an inhibitory effect. In addition, the molecular mechanisms triggered by prolactin seem to differ among lymphoma types such as rat $\mathrm{Nb} 2$ and murine L2 cells. Both are proposed as useful systems for providing information about cellular events dependent on prolactin. However, stimulation of L2 cells caused a 7-fold increase in the prolactin receptor level and an accumulation of prolactin receptor mRNA (24), whereas $\mathrm{Nb} 2$ cells, which likewise require prolactin for growth, responded to the hormone with a rapid increase in prolactin receptor mRNA level; in contrast to $\mathrm{L} 2$ cells, the level of prolactin receptor mRNA declined time-dependently below the baseline after stimulation, suggesting that the level is under negative control (25). Whether these cell types respond differently to different forms of circulating prolactin is not known. Moreover, inhibition of lym-

\section{References}

1. Fukuoka, H., Hamamoto, R. \& Higurashi, M. (1991) Heterogeneity of serum and amniotic fluid prolactin in humans. Horm. Res. 35 (Suppl. 1), 58-63.

2. Ben-David, M. \& Chrambach, A. (1977) Preparation of bio- and immunoreactive human prolactin in milligram amounts from amniotic fluid. Endocrinology 101, 250261.

3. Lewis, U. J., Singh, R. N. P. \& Lewis, L. J. (1989) Two forms of glycosylated human prolactin have different pigeon crop sac-stimulating activities. Endocrinology 124, $1558-1563$.

4. Haro, L. S., Lee, D. W., Singh, N. P., Bee, G., Markoff, E. \& Lewis, U. J. (1990) Glycosylated human prolactin: Alterations in glycosylation pattern modify affinity for lactogen receptor and values in prolactin radioimmunoassay. J. Clin. Endocrinol. Metab. 71, 379-383.

5. Andries, M., Tilemans, D. \& Denef, C. (1992) Isolation of cleaved prolactin variants that stimulate DNA synthesis in specific cell types in rat pituitary cell aggregates in culture. Biochem. J. 281, 393-400.

6. Negami, A. I. \& Tominga, T. (1989) Gland and epithelium formation in vitro from epithelial cells of the human endometrium. Hum. Reprod. 4, 620-627. phocyte proliferation by glucocorticoids was reversed by prolactin in lymphocytes from normal mice, but not in those from tumour-bearing mice (27). Reversal of immunosuppression by prolactin and prolactin secretagogues in normal mice has been confirmed by another report (28). However, prolactin not only modifies the activity of resting and mitogen-induced normal mononuclear immunocytes $(29,30)$. When stimulated, these cells start to synthesize and secrete prolactin forms $(12,31)$, suggesting that prolactins are autocrine growth factors in lymphocytes. Moreover, stimulated mononuclear immunocytes, representing infection stress, produce cytokines such as interleukin 1 and 2, tumour necrosis factor $\alpha$, and $\gamma$-interferon, which induce the hypothalamus to secrete corticoliberin and the pituitary gland to release proopiomelanocortin, interleukin 6 and prolactin $(17,18,32)$.

That generally such stress-related prolactins differ from normal circulating forms is suggested by the present data. Our data also indicate that targetting of the circulating prolactin signals may depend on competition for binding sites. But our experiments do not exclude the existence of specific receptors for signal transduction (33).

The dissimilarities in the properties of the individual prolactin forms, such as receptor-binding affinity (4), and efficacy in a given physiological situation, not only account for the different biological activities of prolactin, but also demonstrate the need for an accurate and physiologically relevant definition and assay of the different forms of prolactin.
7. Löhrke, B., Krüger, B. \& Viergutz, T. (1993) The glycosylation as source of the variability in prolactin patterns of individual human amniotic fluids. Biol. Chem. Hoppe-Seyler 374, $271-279$.

8. Markoff, E. \& Lee, D. W. (1987) Glycosylated prolactin is a major circulating variant in human serum. J. Clin. Endocrinol. Metab. 65, 1102-1106.

9. Subramanian, M. G., Sacco, A. G., Moghissi, K. S., Lawson, D. M. \& Gala, R. D. (1991) Prolactin size beterogeneity in human follicular fluid - A preliminary study. Intern. J. Fertil. 36, 367-371.

10. Champier, J., Claustrat, B., Harthe, C., Chevallier, P. \& Trouillas, J. (1992) Concanavalin A-bound and Concanavalin $\mathrm{A}$-unbound prolactin in normal and hyperprolactinaemic rats. J. Endocrinol. 134, 27-32.

11. Kariya, M., Kanzaki, H., Takakura, 'K., Imai, K., Okamoto, N., Emi, N., Kariya, Y. \& Mori, T. (1992) Interleukin1 inhibits in vitro decidualization of human endometrial stromal cells. J. Clin. Endocrinol. Metab. 73, 1170-1174.

12. Gellerson, B., Bonhoff, A., Hunt, N. \& Bohnet, H. G. (1991) Decidual type prolactin iexpression by the human myometrium. Endocrinology 129, 158-168. 
13. Wu, W. X., Brooks, J., Miller, M. R., Ledger, W. L., Saunders, P. T. K., Glasier, A. \& Mc Neilly, A. S. (1992) Localization of the sites of synthesis and action of prolactin by immunocytochemistry and in situ hybridization within the human utero-placental unit. J. Mol. Endocrinol. 7, $241-247$.

14. Negami, A. I. \& Tominaga, T. (1991) Effects of prolactin on cultured human endometrial cells. Horm. Res. 35 (Suppl. 1), 50-57.

15. Tiemann, U., Löhrke, B., Köwitz, J. \& Alm, H. (1993) Effect of prolactin isolated from human amniotic fluid on cultured bovine cells of the reproductive tract and splenocytes. Reprod. Dom. Anim. 28. in press.

16. Fortier, M. A., Guiband, L. A. \& Gross, F. (1988) Specific properties of epithel and stromal cells from the endometrium of cows. J. Reprod. Fertil. 83, 239-248.

17. Griffin, J. F. (1989) Stress and immunity: An unifying concept. Vet. Immun. Immunopathol. 20, 263-312.

18. Heijnen, C. J., Kavelaars, A. \& Ballieux, R. E. (1991) $\beta$ Endorphin: Cytokine and neuropeptide. Immunol. Rev. $119,41-63$.

19. Carlson, H. E., Markoff, E. \& Lee, D. W. (1992) On the nature of serum prolactin in two patients with macroprolactinemia. Fert. Steril. 58, 78-87.

20. Deb, S., Roby, K. F., Faria, T. N., Larsen, D. \& Soares, M. J. (1991) Identification and immunochemical characterization of a major placental secretory protein related to the prolactin-growth hormone family, prolactin-like protein $C$. Endocrinology 128, 3066-3072.

21. Krown, K. A., Wang, Y. F., Ho, T. W. C., Kelly, P. A. \& Walker, A. M. (1992) Prolactin isoform2 as an autocrine growth factor for GH3 cells. Endocrinology 131, 595-602.

22. Brelje, T. C. \& Sorenson, R. L. (1991) Role of prolactin versus growth hormone on islet B-cell proliferation in vitro: Implications for pregnancy. Endocrinology 128, 45-57.

23. Sinha, Y. N. \& Sorenson, R. L. (1993) Differential effects of glycosylated and nonglycosylated prolactin on islet cell division and insulin secretion. Proc. Soc. Exp. Biol. Med. 203, 123-126.

24. Clevenger, C. V., Russell, D. H., Appasamy, P. M. \& Prystowski, M. B. (1990) Regulation of interleukin2-driven T-lymphocyte proliferation. Proc. Natl. Acad. USA 87, $6460-6464$.
25. Oneal, K. D., Schwarz, L. A. \& Yulee, L. Y. (1991) Prolactin receptor gene expression in lymphoid cells. Mol. Cell. Endocrinol. 82, 127-135.

26. Roby, K. F., Deb, S., Dibori, G., Szpirer, C., Levan, G., Kwok, S. C. M. \& Soares, M. J. (1993) Decidual prolactinrelated protein-identification molecular cloning, and characterization. J. Biol. Chem. 268, 3136-3142.

27. Biswas, R. \& Chattopadhyay, U. (1992) Altered prolactin response of the lymphocytes of tumor-bearing mice. Int. J. Cancer 50, 93-98.

28. Bernton, E., Bryant, H., Holaday, J. \& Dave, J. (1992) Prolactin and prolactin secretagogues reverse immunosuppression in mice treated with cysteamine, glucocorticoids, or cyclosporin-A. Brain Behavior Immunity 6, 394408.

29. Matera, L., Cesano, A., Bellone, G. \& Oberholtzer, E. (1992) Modulatory effect of prolactin on the resting and mitogen-induced activity of lymphocyte- $T$, lymphocyte-B, and lymphocyte-NK. Brain Behavior Immunity 6, 409417.

30. Kelly, K. W., Arkins, S. \& Li, Y. M. (1992) Growth hormone, prolactin, and insulin-like growth factors - New jobs for old players. Brain Behavior Immunity 6, 317326.

31. Sabharwal, P., Glaser, R., Lafuse, W., Varma, S., Liu, Q., Arkins, S., Kooijman, R., Kutz, L., Kelby, R. W. \& Malarkey, W. B. (1992) Prolactin synthesized and secreted by human peripheral blood mononuclear cells: An autocrine growth factor for lymphoproliferation. Proc. Natl. Acad. Sci. USA 89, 7713-7716.

32. Yamaguchi, M., Koike, K., Yoshimoto, Y., Ikegami, H., Miyake, A. \& Tanizawa, O. (1991) Effect of TNF-alpha on prolactin secretion from rat anterior pituitary and dopamine release from the hypothalamus - Comparison with the effect of interleukin-1. Endocrinol. Japon. 38, 354361.

33. Kelly, P. A., Djiane, J. \& Edery, M. (1992) Different forms of the prolactin receptor-insights into the mechanism of prolactin action. Trends Endocrinol. Metab. 3, 54-59.

Dr. B. Löhrke
Forschüngsinstitut für die
Biologie landwirtschaftlicher Nutztiere
Forschungsbereich Populationsbiologie
und Züchtungsforschung
Wilhelm-Stahl-Allee 2
D-18196 Dummerstorf
Germany

Dr. B. Löhrke

Forschungsinstitut fur die

Forschungsbereich Populationsbiologie und Züchtungsforschung

D-18196 Dummerstorf

Germany 
